survey of mental health trusts and health authority purchasers. Psychiatric Bulletin, 24, 169-171.

SANDOR, A. \& ORME, S. (2000) Home treatment teams (letter). Psychiatric Bulletin, 24, 394.

SMYTH, M. G. \& HOULT, J. (2000) The home treatment enigma. British Medical Journal, 320, 305-309.

Andrew Owen Specialist Registrar,

S. P. Sashidharan Consultant Psychiatrist and Medical Director, Northern Birmingham Menta Health NHS Trust, Medical Directorate, 71 Fentham Road, Erdington, Birmingham B23 6AL

\section{Prescribing and monitoring of valproate}

Sir: The authors of a recent paper (Taylor et al, 2000) have drawn much-needed attention to the high prevalence of subtherapeutic treatment of conditions such as mood disorders with carbamazepine or valproate. However, the authors have given much emphasis to the use of drug serum levels in monitoring the use of both these drugs in such conditions.

Personal experience suggests that there are potential pitfalls for the unwary in the interpretation of valproate levels. In particular, in a minority of patients it may be impossible to reach the stated trough threshold level of $50 \mathrm{mg} / \mathrm{l}$, even at daily doses in excess of the licensed maximum and despite supervised compliance.

One possible reason for this is that valproate is highly (about 90\%) bound to plasma protein at low body levels, but with increasing doses the binding sites become saturated and free levels rise. More active drug is thereby delivered to the central nervous system (CNS) (Dollery, 1991) without in some cases more than a marginal rise in measured (bound plus unbound) serum levels. This effect should be borne in mind if measured levels do not rise in proportion to a dose increase in a particular case.

Other factors confounding the interpretation of valproate levels include the fact that: the effects in the CNS considerably outlive the detectable presence of the drug in the body, possibly because of active metabolites; there is variable displacement from serum binding sites by free fatty acids; blood samples taken just before a dose may not consistently represent trough levels, because of possible entero-hepatic recirculation and diurnal variation in elimination (Chapman et al, 1982; Dollery, 1991). These factors explain, at least in part, why valproate measurements tend to be unreliable for some clinical purposes.

CHAPMAN, A , KEANE, P. E, MELDRUM, B. S et al (1982) Mechanism of anticonvulsant action of valproate. Progress in Neurobiology, 19, 315-359.

DOLLERY, C. (ed.) (1991) Therapeutic Drugs. Vol. 2 Sodium Valproate. Edinburgh: Churchill Livingstone.

TAYLOR, D. M., STARKEY, K. \& GINARY, S. (2000) Prescribing and monitoring of carbamazepine and valproate - a case note review. Psychiatric Bulletin 24, 174-177.

David Armour Senior Pharmacist, Pharmacy Department, Springfield University Hospital, 6 Genburnie Road, London SW17 $7 \mathrm{D}$

\section{Changes to the MRCPsych examinations}

Sir: Although the forthcoming changes to the Part I and II MRCPsych Examinations are on the whole welcome news (Katona et al, 2000), I hold several reservations regarding some of the alterations proposed.

After several years of post-graduate experience in psychiatry I sat an Observed Structured Clinical Examination as part of the Licentiate of the Medical Council of Canada. I had concerns about the inherent validity of the psychiatric section of the examination, which at times was clearly role-play. By including actors in psychiatric examinations, are we not making unnecessary and unwelcome changes?

Experience in the long case is equally if not more valuable to those who fail as to those who pass the membership examinations, and I feel disappointed this will now be subject to screening procedures in Part II, particularly as it has been removed from Part I. Denying experience of a long case until Part II, and lessening the emphasis on history-taking, may delay development of those skills gained in preparing for this aspect of the examina tion, many of which are fundamental to good clinical practice.

Should changes to our examinations not be moving us closer to rather than further from 'real world' psychiatry?

KATONA, C., TYRER, S. P. \& SMALLS, J. (2000) Changes to the MRCPsych examinations. Psychiatric Bulletin, 24, 276-278.

Mark C. Dale Honorary Senior Lecturer and Consultant Old Age Psychiatrist, Fleetwood Hospital, Pharos Street, Fleetwood FY6 6BE

\section{Junior doctors' pay deal}

Sir: From December 2000, additional duty hours will be replaced by a banding system based on the time spent 'actually working' on call. Psychiatry trainees will be paid significantly less than their colleagues in other specialities, who have shorter rest periods. While to an extent this is justified, the size of the pay differential is alarming and the higher level of stress experienced by psychiatrists (Dreary et al, 1996) is not recognised.

A house officer choosing a career may be faced with either a pay cut of $f 48$ per year to take up psychiatry or a raise of f6413 per year to do general medicine. With the introduction of tuition fees, the British Medical Association estimates that the debts of final year medical students will rise from an average of $f 7738$ in 1998 (Brooks, 1998) to up to $f 25000$ (British Medical Association, 1997). This will have grave implications for recruitment to psychiatry. The College needs to address this issue if it wants to attract doctors into our speciality.

\section{BRITISH MEDICAL ASSOCIATION (1997) Briefing.} British Medical Journal, 315, 7107.

BROOKS, A. (1998) Medicine may become'domain of the privileged'. British Medical Journal, 317, 558.

DREARY, I. H., BLENKIN, H., AGIUS, R., et al (1996) Models of job-related stress and personal achievement among consultant doctors. British Journal of Psychology, 87, 3-29.

Peter Roots Devon House Adult Psychotherapy Service, MindelsohnWay, Edgbaston, Birmingham B15 2QR

\section{Introducing The Royal College of Psychiatrists' Cricket Club}

Sir: I seek to reach readers who are interested in playing cricket. I intend to gather names of Inceptors, Members and Fellows of the College who support the idea of founding The Royal College of Psychiatrists' Cricket Club and also of those who are keen to play for the College.

If you are interested, please send me your name and address, with a brief playing history.

Fawad Kaiser Kneesworth House Psychiatric Hospital, Bassingbourn-cum-Kneesworth, Royston SG8 5JP 